\title{
Digital Literacies for Ministry: A Qualitative Study of Theological Educators Preparing Students for New Media Engagement
}

\author{
Kyle Matthew Oliver \\ Doctoral Candidate, Communication, Media, and Learning Technologies \\ Design Program, Teachers College, Columbia University, New York, UsA \\ kmo2144@tc.columbia.edu \\ Stacy Williams-Duncan \\ Doctoral Candidate, Curriculum and Instruction, Curry School of Education, \\ University of Virginia, Charlottesville, Virginia, USA \\ swilliams-duncan@vts.edu \\ Elisabeth M. Kimball \\ James Maxwell Professor of Lifelong Christian Formation, Virginia \\ Theological Seminary, Alexandria, Virginia, UsA \\ lkimball@vts.edu
}

\begin{abstract}
The proliferation of religious and spiritual practices in new media spaces presents challenges and opportunities for religious leaders-and for the people who train them. This article reports on an interview-based study of theological educators actively engaged in preparing their students with skills and experiences for online engagement. We present and discuss seven digital literacies for ministry that emerged from our thematic analysis of transcript data and were subsequently refined with a subset of study participants. We conclude with a brief discussion of new initiatives this research has prompted.
\end{abstract}




\section{Keywords}

digital literacy - leadership practices - new media - theological education - digital literacies for ministry

\section{Background and Motivation}

One of the most prominent authorities on pedagogical and technological practices in Christian seminaries, Mary Hess, observes that these institutions' attention tends to focus on the technical challenges of implementing new systems for managing students and delivering content rather than the more adaptive challenges of fostering 'energetic, critical, and adept leadership' for cultures in which technology is integrated 'into almost all of our daily practices.' While this situation has improved incrementally since 2005, there is much work yet to be done. There is an urgent need for concrete models that will help seminaries respond theoretically and programmatically to this question: What training do religious leaders need in order to do their work effectively in the age of new media?

Against the social backdrop of diminishing civic participation in general and religious affiliation, observance, and vitality in particular, the rise of the Internet has been seen by faith communities in the United States and beyond as both threat and opportunity. ${ }^{2}$ Originally envisioned as a separate, secular sphere of individual and communal activity ('cyberspace,' 'the virtual world,' etc.), new media spaces and tools are now far more likely to be integrated within the day-to-day lives of the many users of increasingly mobile, broadbandconnected, socially networked technologies. ${ }^{3}$

This integrated perspective is evidenced in the work of multiple leaders in this field. Religion writer Elizabeth Drescher explains the faith dimension of this transition as an evolving 'improvisational habitus' shaping contemporary

1 M. E. Hess, Engaging technology in theological education: All that we can't leave behind (Lanham, MD: Sheed \& Ward, 2005), p. 2.

2 R. D. Putnam, Bowling alone: The collapse and revival of American community (New York, NY: Simon and Schuster), 2000; C. Smith \& P. Snell, Souls in transition: The religious and spiritual lives of emerging adults (New York, NY: Oxford University Press), 2009; Pew Research Center, 'U.S. public becoming less religious,' (2015). http://www.pewforum.org/2015/11/03/u-s-public -becoming-less-religious/; D. A. Roozen, 'American congregations 2015: Thriving and surviving (Faith Communities Today),' (Hartford, CT: Hartford Institute for Religion Research), 2015 .

3 L. Rainie, \& B. Wellman, Networked: The new social operating system, (Cambridge, MA: MIT Press), 2012. 
religious practice. ${ }^{4}$ Communication researcher Heidi Campbell describes networked religion's new 'multisite reality' where 'interconnection between online and offline contexts' converge. ${ }^{5}$ Lutheran pastor Keith Anderson captures it with the metaphor of a 'digital cathedral,' wherein socially networked and mobile technologies free faith communities to embed themselves in their neighborhoods in a way that mirrors how medieval cathedrals served as integrated centers of social, commercial, and municipal life in communities. ${ }^{6}$ Understood in these ways, new media begins to look less like an outside force to be mitigated or leveraged and more like the water in which we swim-and minister.

Our research represents a first step in responding directly to the need for concrete models that support theological educators and ministry practitioners in responding adaptively to the digital realities of our world. This paper reports on an interview-based qualitative study that sought to identify common practices from across seminaries and other institutions of church leadership preparation. We gathered and organized insights from participants in theological education who have been active as researchers or instructors at the intersection of new media and communities of faith. These participants helped us to identify seven digital literacies for ministry: practices for leading ecclesial communities in the twenty-first century.

\section{Literature Review}

An important source of guidance for theological educators hoping to better prepare students for ministry today have been practitioner-oriented handbooks. These volumes tend to bring together (1) theological reflection on integrating new media in ministry and (2) practical guidance and strategies for conducting that integration effectively, especially in and on behalf of congregations. ${ }^{7}$ A consensus seems to be emerging in this genre that principles, case

4 E. Drescher, Tweet if you [heart] Jesus: Practicing church in the digital reformation, (New York, NY: Morehouse Publishing), 2011, p. 46.

5 H. A. Campbell, 'Understanding the relationship between religion online and offline in a networked society,' Journal of the American Academy of Religion 8o (2012), pp. 80-83 doi:10.1093/jaarel/lfro74.

6 K. Anderson, The digital cathedral: Networked ministry in a wireless world, (New York, NY: Morehouse Publishing), 2015.

7 L.M. Baab, Reaching out in a networked world: Expressing your congregation's heart and soul. (Lanham, MD: Rowman \& Littlefield), 2008; E. Drescher, Tweet if you [heart] Jesus; B. ReyesChow, The definitive-ish guide for using social media in the church, (Los Angeles, CA: Shook Foil Books), 2012; E. Drescher, \& K. Anderson, Click 2 save: The digital ministry bible, (New York, NY: Church Publishing), 2012; J. Naughton, \& R. Wilson, Speaking faithfully: Communications 
studies, and theological reflection for guiding the work are more useful (and certainly have a longer 'shelf life') than more instrumentalist how-to content and detailed procedural guides. A missing component in existing literature is the integration of perspectives from across theological disciplines and areas of ministry practice in order to provide a holistic understanding of, to use our preferred term, digital literacy. ${ }^{8}$

A leading university offering graduate studies in digital literacy describes this concept as "knowledge, skills and competencies required to participate in our read/write culture," with "[a]ctive participation ... defined as being able to skillfully use, create and share digital texts, tools and technologies." ${ }^{9}$ We identified three theological educators who have written explicitly about digital literacies within theological education and how those literacies influence religious leadership. Zsupan-Jerome provides a theoretical comparison of secular and ecclesial practice of different levels of digital literacy. ${ }^{10}$ Copeland argues that digital literacies are the current day manifestation of strong communication practices, which have always been paramount in ministry. ${ }^{11}$ Hess' work provides the most integrated and comprehensive vision of the importance of digital literacies in ministry. For each of these scholars, to develop one's digital literacy is not to be trendy or even just pragmatic but in fact deeply faithful to God's mission for the church in a changing world.

Zsupan-Jerome compares a model proposed in a secular context by Martin and Grudziecki to the Congregation for Catholic Education's seminal Guide to the Training of Future Priests Concerning the Instruments of Social

as evangelism in a noisy world, (New York, NY: Church Publishing), 2012; A. J. Lytle, Faith formation 4.o: Introducing an ecology of faith in a digital age, (New York, NY: Morehouse), 2013; J. Caston, The iChurch method: How to advance your ministry online, (Frisco, TX: Caston Digital Publishing), 2012; K. Anderson, The digital cathedral; M. Gould, The social media gospel: Sharing the good news in new ways (Second edition), (Collegeville, MN: Liturgical Press), 2015; J. Roberto, Reimagining faith formation for the 21st century: Engaging all ages and generations, (Naugatuck, CT: Lifelong Faith Publications), 2015; H. Herring, \& T. M. Elton, Leading congregations and nonprofits in a connected world: Platforms, people, and purpose, (Lanham, MD: Rowman \& Littlefield), 2016.

For an accessible and concise history of the strands of literacy studies that come together to inform the concept of digital literacy, see L. Vasudevan, 'Education remix: New media, literacies, and the emerging digital geographies,' Digital Culture \& Education 2 (2010), pp. 62-82.

$9 \quad$ University of Rhode Island College of Education and Professional Studies, Certificate of graduate study in digital literacy, (2019). https://web.uri.edu/prov/certificate-credit-and -non-credit-program/digitalliteracy/.

10 D. Zsupan-Jerome, Connected toward communion: The church and social communication in the digital age, (Collegeville, MN: Liturgical Press), 2014.

11 A. J. Copeland, 'Writing digitally,' in Writing theologically, edited by E. D. Barreto, (Minneapolis, MN: Augsburg Fortress), 2015, pp. 87-102. 
Communication. ${ }^{12}$ Martin and Grudziecki propose a three-tiered system wherein 'digital competence' affords basic skills in understanding, navigating, and evaluating new media communication; 'digital usage' requires applying competence 'within specific professional or domain contexts' and 'digital transformation ... enable[s] innovation and creativity, and stimulate[s] significant change within the professional or knowledge domain.' ${ }^{13}$

The Guide offers its own three levels: 'basic,' 'pastoral,' and 'specialist.' All Catholics are expected to receive basic formation so as not to be susceptible to manipulation by the media, especially as to matters of doctrine, ethics, etc. All priests should receive pastoral training to help discern the right use of media, to provide guidance to those media professionals who might be under their pastoral care, and to 'make the necessary adjustments in their pastoral activity, including those demanded by the inculturation of the Christian faith and life in the different particular churches, in a world psychologically and socially conditioned by the mass media and even already by telematics and informatics.' ${ }^{14}$ Finally, some priests are to become media specialists, receiving training either in Catholic centers or public institutions. ${ }^{15}$ Zsupan-Jerome emphasizes that, given our modern participatory cultures, ${ }^{16}$ such a pyramid schematic, with only a small number of specialists reaching the top level of experience and fluency, will no longer suffice.

Like Zsupan-Jerome, Copeland sets up the challenge of digital literacy as a matter of responding faithfully to social context:

Becoming digitally literate requires you to pursue questions like, How are God's people communicating today? On what platforms is digital writing occurring? When is technology mediating our lives? Digital literacy ... warrant[s] a basic understanding of how digital communication technologies affect our life together. ${ }^{17}$

12 A. Martin, \& J. Grudziecki, 'DigEuLit: concepts and tools for digital literacy development,' Innovation in Teaching and Learning in Information and Computer Sciences 5 (2006), pp. 1-19; Congregation for Catholic Education, 'Guide to the training of future priests concerning the instruments of social communication,' (1986). http://www.vatican.va/roman curia/pontifical_councils/pccs/documents/rc_pc_pccs_doc_19031986_guide-for -future-priests_en.html.

13 A. Martin, \& J. Grudziecki, pp. 9-11.

14 Congregation for Catholic Education, n. p.

15 Ibid.

16 See H. Jenkins, R. Purushotma, M. Weigel, K. Clinton, \& A. J. Robison, Confronting the challenges of participatory culture: Media education for the 21st century, (Cambridge, MA: MIT Press), 2009.

17 Copeland, p. 87. 
Copeland acknowledges that effective online communication requires not just technical know-how but 'digital wisdom,' analogous to 'theological, biblical, ecclesial, and pastoral forms of wisdom' and developed within and beyond the classroom through 'a combination of [students'] own initiative, the collegiality of student peers, and the support of ... faculty'18 Copeland explicitly acknowledges that many faculty lack the training and confidence to teach and promote digital literacy.

When he comes to naming concrete skills students should pursue, he includes the mechanics of interaction via online platforms, stylistic facility (both linguistic and behavioral) in new media spaces and genres, and several of the new media literacies that come from Jenkins and colleagues' participatory cultures work: appropriation (aka remixing), multitasking, collective intelligence (aka crowdsourcing), and play. ${ }^{19}$ Copeland's work reminds us that reading and writing have always been important to ministers - not just during their training but in their ministry. The increasing digital mediation of social interaction only increases this importance.

Hess identifies explicitly as a media literacy educator working within theological education and has long advocated that religious communities and their leaders need to reckon with media cultures. ${ }^{20} \mathrm{~A}$ recent thread of Hess's writing has been on the promise of new media pedagogies in faith forming activities, including digital storytelling ${ }^{21}$ and 'gameful learning.'.

Hess's interest in digital storytelling stems in part from the medium's encouragement of practices of attention, reflection, and empathy-building. ${ }^{23} \mathrm{But}$ this commendation also seems to be related to her broader vision of faith communities learning to embody Jenkins's new media literacies: play, performance,

18 Ibid, pp. 87-88.

19 Ibid, pp. 97-101.

20 M. E. Hess, 'Learning with digital technologies: Privileging persons over machines,' Journal of Moral Theology 4 (2015), pp. 131-50; M. E. Hess, "Mirror neurons, the development of empathy, and digital story telling," Religious Education 107 (2012), pp. 401-414; M. E. Hess, 'Practising attention in media culture,' In Mediating religion: Conversations in media, religion and culture, edited by J. Mitchell and S. Marriage, (New York, NY: T\&T Clark), 2003, pp. 133-142; M. E. Hess, 'Rescripting religious education in media culture.' In Belief in media: Cultural perspectives on media and Christianity edited by P. Horsfield, M. E. Hess, and Adán M. Medrano, (Burlington, VT: Ashgate), 2004, pp. 153-164; M. E, Hess, Engaging technology in theological education.

21 A methodological term of art. See J. Lambert, Digital storytelling: Capturing lives, creating community, (New York, NY: Routledge), 2012.

22 M. E. Hess, Mirror neurons; M. E. Hess, 'A new culture of learning: Digital storytelling and faith formation,' Dialog: A Journal of Theology, 53 (2014), pp. 12-22; Hess, Mary E. "Playing Our Way into Complex Adaptive Action in Religious Education." In Proceedings of the Religious Education Association Annual Meeting. Pittsburgh, PA, 2016. 
appropriation, simulation, etc. ${ }^{24}$ Through immersion in this "new culture of learning," Hess hopes that we will develop capacities for meeting the big challenges facing faith communities today:

Can we embody religious education that educates within and for specific religious communities, but also and concurrently with and for people who are not part of religious communities? Can we reach people who might have very little interest in, or perhaps even hostility towards, religious institutions? I fear that until and unless religious communities can communicate - in all the rich senses of that word - our integral and inextricable commitments to relationship across, among, within, between and amidst various kinds of difference, we will lose even more ground with a generation of people growing to consciousness within the rich and varied landscapes of the US. ${ }^{25}$

In our reading of Hess, the social practice ${ }^{26}$ of digital literacy-embedded in the broader cultural commitments through which it is developed-is nothing less than sacramental embodiment of faith communities' call to relationality within and beyond existing boundaries. One purpose of this study is to put flesh on the skeleton of that body, demonstrating ways that both innovative and more mainstream communities are seeking and serving in, through, and with digital spaces and tools, and exploring the meaning of these actions for theological education.

\section{3}

\section{Methodology}

One goal of this project was to build relationships among innovative theological education practitioners and connect their wisdom and experiences. Thus, the study had a bimodal design: part qualitative educational research seeking to identify common thinking and wise practices, part action research and community organizing seeking to commend available assets and bring together

24 M. E. Hess, 'Learning with digital technologies: Privileging persons over machines,' Journal of Moral Theology 4 (2015), pp. 131-50.

25 Hess, Playing Our Way, p. 1, emphasis added.

26 B. V. Street, Social literacies: Critical approaches to literacy in development, ethnography and education, (New York, NY: Routledge), 1995; J. P. Gee, 'The New Literacy Studies: From "socially situated" to the work of the social.' In Situated literacies: Reading and writing in context edited by D. Barton, M. Hamilton, and R. Ivanič, (New York, NY: Routledge), 200o, pp. $180-196$. 


\section{Participant (Interview Date) Context}

\begin{tabular}{|c|c|}
\hline 1 (Sept 2015) & 2 Southern Universities \\
\hline $35($ online - April 2016) & \\
\hline $2-6($ Oct 2015$)$ & 4 Midwestern Seminaries \\
\hline \multicolumn{2}{|l|}{$8-9($ Oct 2015) } \\
\hline \multicolumn{2}{|l|}{$10-11($ Oct 2015) } \\
\hline \multicolumn{2}{|l|}{12 (online - Nov 2015) } \\
\hline $7($ Oct 2015) & Midwestern University \\
\hline $13($ online - Dec 2015) & 3 Northeastern Universities \\
\hline \multicolumn{2}{|l|}{$14($ Feb 2016) } \\
\hline \multicolumn{2}{|l|}{$36($ online - May 2016) } \\
\hline 15-21 (April 2016) & $\begin{array}{l}\text { Denominational Ethnic Ministries } \\
\text { Office }\end{array}$ \\
\hline 22-27 (April 2016) & 3 Western Seminaries \\
\hline 28-29 (April 2016) & \\
\hline 30-31 (April 2016) & \\
\hline 32-34 (April 2016) & Western University \\
\hline
\end{tabular}

potential collaborators. ${ }^{27}$ This approach placed a rich and sometimes challenging tension at the center of our activities, from participant recruitment to analysis and reporting.

Our primary research activity in this qualitative study was a series of 19 protocol-based, ${ }^{28}$ semi-structured interviews $(15$ in person, 4 via video conference) conducted by Oliver with 36 leaders in 13 ministry training organizations. The interviews lasted 45-90 minutes depending on participants' availability and interest. In some of the institutions we contacted, multiple people expressed interest and participated. Our judgment about the significance of particular participants' expertise, as well as travel and availability constraints, dictated whether we interviewed participants separately or in focus-groups. Within the limits of participant anonymity, we have summarized these interviews in Table 1.

27 J. P. Kretzmann, \& J. McKnight, Building communities from the inside out, (Evanston, IL: Center for Urban Affairs and Policy Research), 1993.

28 We have made the protocol available for download at https://www.digitalliteracytoolkit .org/research/. 
This fairly large participant sample allowed us to address our research questions in a manner that took into account the voices of a large and diverse community of practitioners, allowed us to help grow connections among a network of collaborators, and indeed in some cases connected colleagues who had never met and whose teaching and research was little known to each other despite common interests. In short, we knew we were conducting research that could have an impact on pedagogical practice in theological education, so we sought a sample that could build buy-in through broad participation in the work.

Since there exists relatively little systematic, theoretical literature in this area, we used a grounded theory approach to analysing the interview transcripts. Most of the data that contributed to this paper came in response to the questions: (1) What digital media ministry skills are most important for ministers and ministry students? (2) How do you personally (or your institution) help students develop these skills?

The interview recordings were transcribed by a reputable social science research support firm and qualitative coding software was used for analysis. In one case, we failed to inform the participant when making the appointment that the conversation would be recorded, so our analysis of this interview was based on Oliver's field notes.

All participants had professional interest in preparing students with skills for ministry with/in digital media tools and spaces, although their practical experience and levels of expertise varied. The initial set of participants served both our 'community organizer' interests, providing a discrete occasion to form relationships with practitioners whose work we respected, and our desire to begin forming consensus among acknowledged experts. ${ }^{29}$

Additional participants were identified by other study participants via snowball sampling. ${ }^{30}$ Incorporating the 'snowball' procedure filled in some gaps in our knowledge of theological educators active in this area (increasing our confidence that we were gathering a significant sample of relevant scholars) and allowed us to leverage 'natural and organic social networks' to which our participants belong (increasing our chances of ultimately mobilizing this community for later collective action). ${ }^{31}$

Following a pilot conversation, which helped us test and make small refinements to our protocol, and subsequent 'first round' of six interviews, Oliver conducted a coding pass and presented on emerging themes to

29 N. M. Bradburn, S. Sudman, \& B. Wansink, Asking questions: The definitive guide to questionnaire design. $2^{\text {nd }}$ ed, (San Francisco, CA: Jossey-Bass), 2004.

3o C. Noy, 'Sampling knowledge: The hermeneutics of snowball sampling in qualitative research,' International Journal of Social Research Methodology 11 (2008), pp. 327-344.

31 Ibid, p. 329. 
Williams-Duncan and Kimball. In accordance with the grounded theory principle that 'analyzed data guides subsequent data collection', we elected to focus the bulk of subsequent interviews on the first two conceptual groupings of questions in the protocol (digital media skills and how to teach them) in order to allow for more in-depth conversations about a smaller number of topics. ${ }^{32}$ Oliver then conducted the remaining 12 interviews and coded a purposely selected subset of transcripts.

After a second revision of the coding framework, Oliver, Williams-Duncan, and Kimball presented it and preliminary analysis to seven study participants and four other theological educators who attended an in-person symposium. This gathering served the community-organizing component of the study, giving participants an opportunity to meet and to digest together the studies' findings and implications for possible shared action.

The gathering also had a participatory-analytical component, inviting subjects' 'direct involvement in the co-construction of meanings' in the study. ${ }^{33}$ This methodological approach of increased participant agency supported our desire to leverage the expertise of key contributors in this emerging field. This was crucial in further refining our coding framework, especially in shaping its vocabulary in a way that we believe has made our theorizing more relevant and accessible to an audience of theological educators. After the symposium, Oliver, Williams-Duncan, and Kimball completed the final revision to the coding framework and Oliver re-coded the transcripts. In the midst of this final round of analysis, Oliver and Kimball presented intermediate findings at a conference for religious educators. ${ }^{34}$

\section{$4 \quad$ Results}

The principle findings reported in this special issue on digital ecclesiology is a framework of seven digital literacies for ministry. The names and groupings for these (non-mutually exclusive) literacies are intended to communicate clearly to and resonate among church leaders and theological educators. We have phrased them in the gerund form (e.g., 'navigating hybrid and digital cultures' rather than 'ability to navigate ...') to emphasize that learning and practicing

32 J. Y. Cho, \& E. Lee, "Reducing confusion about grounded theory and qualitative content analysis: Similarities and differences," The Qualitative Report, 19 (2014), pp. 1-20.

33 A. Clark, "Multimodal map making with young children: Exploring ethnographic and participatory methods," Qualitative Research 11 (2011), p. 311.

34 K. M. Oliver, E. M. Kimball, S. Williams-Duncan, \& I. Blanchard, 'Digital media for ministry asset mapping: An exploratory study in theological education,' (2016). https://religiouseducation.net/papers/rea2o16-oliverı.pdf. 

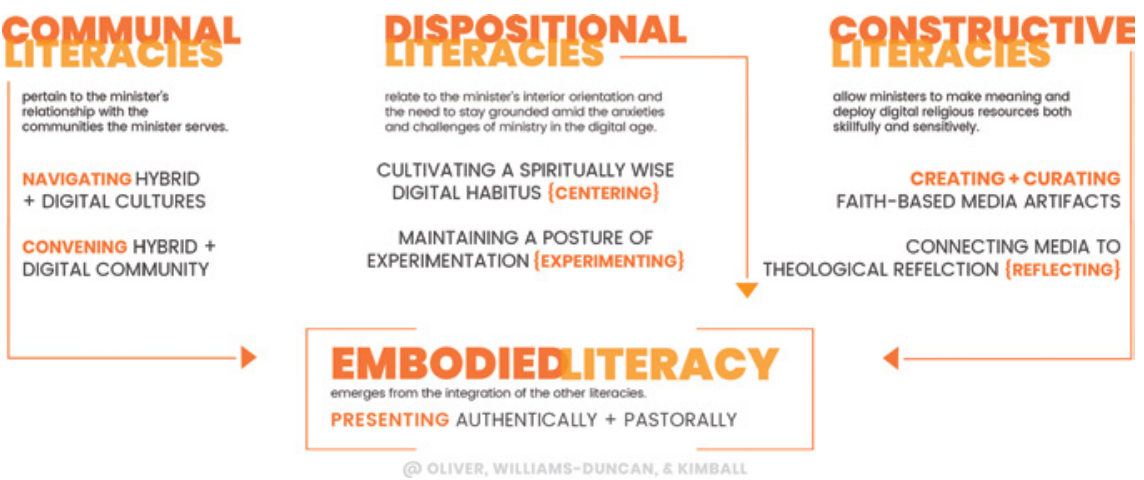

FIGURE 1 The names, groupings, and conceptual relationships between the seven digital literacies.

them is a matter of ongoing formation-especially since the media and technologies involved are always changing. All italics in the interview excerpts have been added for emphasis.

These literacies emerged in thematic clusters from our early analysis. Deciding how to group and describe common answers was the most intensive challenge of our research team's conceptual decisions and coding and was a source of significant conversation at our participant symposium. In our discussion below, we define each literacy and offer two representative excerpts from our interviews and a short list of ministry tasks that more fully illustrate the breadth of the particular literacy. We realize that in deciding to report the findings in a comprehensive way, i.e., the entire list of seven literacies presented as a framework, we have limited the treatment we can give to each one. As education scholars frequently responsible for helping colleagues across the theological disciplines efficiently conceptualize and pedagogically respond to their students' engagement with digital literacy, we believe the benefits of presenting the framework in a single foundational article justify the limitations imposed by this decision. Subsequent published ${ }^{35}$ and planned articles treat subsets of the literacies in more detail.

\subsection{Communal Literacies}

The first pair of literacies is primarily communal. They pertain to the minister's relationship with the communities the minister serves.

Navigating hybrid and digital cultures is the ability to move confidently and competently through many relevant online spaces and communities,

35 K. M. Oliver, \& S. Williams-Duncan, "Faith leaders developing digital literacies: Demands and resources across career stages according to theological educators," Journal of Media Literacy Education 11 (2019), pp. 122-145. 
including those that have a strong correlation to a particular face-to-face community.

One student [did] a lot of research into other LG BTQ pastor Tumblrs. He uncovered quite a few of them ... Ev'ry Day I'm Pastorin' hit the nail on the head. It was just an exemplary use of Tumblr. That use of the gif and the humor. He was like, 'I'm not really a pastor. I don't really go to church. I don't know much about it, and yet I feel like I can understand and relate to all this. I would read this Tumblr just because it's funny and it's interesting.'

This excerpt offers a concrete example of contextually appropriate participation in a particular online community. It also illustrates the rhetorical power and social cachet derived from savvy and accessible new media participation.

I wonder, too, about ways in which we encourage people to move conversations online or offline. When does a conversation that begins in person, when would it really be helpful to spread that network of connections further? When does it makes sense to help people know how to discern when to come offline? To know the balance between the limits of a particular medium.

This excerpt illustrates the relationship between online and offline conversation and helped to clarify for us the need to refer explicitly in the literacy name to hybrid spaces-i.e., sites of social presence that incorporate both online and in-person engagement.

Relevant ministry tasks:

- understand and use the social conventions of relevant networking tools;

- determine the websites, blogs, message boards, and groups where members of a particular community spend time online;

- identify bias and credibility of people and platforms online;

- communicate effectively with others both in person and online;

- know when an online conversation should move offline and when an offline conversation should move online.

Convening hybrid and digital community is the ability to bring together groups online and help them flourish as communities-learning from, supporting, and otherwise engaging with each other. These are 'Art of Hosting'-type skills applied online. ${ }^{36}$

36 J. Brown \& D. Isaacs, The World Café: Shaping our futures through conversations that matter, (San Francisco, CA: Berrett-Koehler Publishers), 2005. 
The age-old question [is] how do you get people to engage? Just because it's easy to engage doesn't mean that people will and it doesn't mean that they will consistently. If you're developing a digital strategy as part of your adult ed program or whatever, the question remains, how do you get people to buy in? When there's no real carrot and there's no real stick, how do you get them to really be engaged?

This excerpt highlights the continuity of this particular literacy with the connectional and organizational work that faith community leaders have always done-and often struggled with. Inviting engagement seems to be especially critical in light of declines in traditional measures of in-person religious participation.

I can have students straight out of college who hate technology because their only experience of it is the worst elements ... They never learned how to be a part of real conversations. They never learned how to shape relationships ... and so they are deeply almost scarred by it, right?

This excerpt explicitly raises a common participant observation: that there is no simple correlation between age and comfort or skill ministering in digital spaces. In fact, several participants told stories of young seminarians boldly (and with technical proficiency) taking community issues to social media in ways that failed to consider the relational complexities of ministry.

Relevant ministry tasks:

- organize groups of people online

- get members of a community talking to each other not just to the facilitator

- negotiate and enforce group and community norms

- invite increased participation in community activities

- share leadership responsibilities with other members of a group

\subsection{Dispositional Literacies}

The second pair of literacies relates to the minister's interior orientation to ministry in the new media age. They underscore the need to stay grounded amid the anxieties and challenges of this changing work.

Cultivating a spiritually wise digital habitus is the ability to apply the insights of spiritual traditions to the daily practice of digitally mediated social participation, making it more manageable and mindful.

[Students need] first and foremost, the ability to listen carefully ... I just think we're swirling right now. We're in a context [of a] fire hose of data, 
which isn't even information, and little opportunity to learn the practices of deep community ... there's a certain kind of unplugging from devices and being in silence, but just doing it in isolation [is problematic] ... Even monks are always in community.

Most everyone who engages with digital devices could rightly be described as 'swirling' in light of the speed, chaos, and volume associated with new media cultures. The mindful use of technology for leaders of faith communities is important both for their own spiritual health and so that they can be effective modelers of these healthy practices for the people they serve. One of the valuable contributions that faith communities can make to today's world is applying the wisdom of our traditions to the development of critical habits for technology use.

When a student in ministry leaves an appointment, then do you unfriend every Facebook friend that you have from the previous congregation? ... [That] is the standard of practice for the time - the ancient time-prior to digital media. You didn't keep in touch with people from congregations. [It] actually raise[s] a broader set of categories, I think. Boundary questions as a whole, not just transition boundary questions.

This reflection shows that the wise practices of one era may require adaptation under the new media ecology. Moreover, such a process will be a matter of continual re-negotiation, including with existing ecclesial guidelines. ${ }^{37}$

Relevant ministry tasks:

- customize digital tools (notifications, etc.) to balance between necessary connectedness and information overload

- plan and practice periods of technology Sabbath

- set and enforce appropriate personal boundaries with digital tools and in digital spaces

- use digital artifacts and tools as prayer prompts and accountability aids

- focus and thrive amid the temptation of digital interruption

Maintaining a posture of experimentation means an orientation that will allow ministers to explore new tools, try out strategies, tolerate and learn from apparent failures, and otherwise innovate in a fast-changing digital landscape.

The literacy of the twenty-first century is the ability to learn, to unlearn, and to learn again. 
This excerpt succinctly states what it takes to do ministry during a time of intense social change. Indeed, reflective practice and innovation in digital social spaces go hand in hand with the process of identifying ministry models better calibrated to the realities of twenty-first century society in developed nations and elsewhere. ${ }^{38}$

I'm ... about making mistakes, giving things a shot, learning from an experimental attitude. It may be a complete disaster, and I've told them that multiple times. 'I've never done this. Who knows?' [Use] the educational experience as an opportunity for wonder and experimentation or to just see what happens.

A necessary part of experiential learning - in seminary and especially beyond-is the repeated experience of failure and its usefulness in discernment, planning, and creativity. ${ }^{39}$ We know both that fear of failure has held back some of our own efforts in this space and that the reality of failure has clarified our work in some pivotal moments. The practice of 'startup' technology companies structuring their business development cycle on failure-adaptive 'pivots' evidences a fitting — and probably not coincidental— resonance with this set of excerpts from our participants.

Relevant ministry tasks:

- learn new tools and assess their relevance for ministry

- respond to both explicit feedback and reflection on experience

- manage anxiety in the midst of trying something new

- identify, implement, and assess manageable next steps in developing new ministries

- revise digital products and processes after examining data about their use

\subsection{Constructive Literacies}

The final literacy pairing allows ministers to make meaning online. They address the need to deploy digital religious resources both skillfully and sensitively.

Creating and curating faith-based media artifacts is a ministry task that allows leaders to teach faith content, initiate theological reflection with their communities, and otherwise leverage high-quality religious resources at a time

38 Leaders engaged in such work include K. Anderson, J. Roberto, and H. Herring and T. M. Elton.

39 For a pedagogical approach to improving seminarians' comfort with this reality and style of learning, see K. M. Oliver, 'Networked religion meets digital geographies: Pedagogical principles for exploring new spaces and roles in the seminary classroom,' Teaching Theology \& Religion 22 (2019), p. 3-15. 
when it is harder than ever for untrained eyes to identify material appropriate to one's tradition.

You work first on helping them tell their own story and so create a story. In the process of taking that story and embedding it in some format that is sharable ... you end up having to slow down and listen to your story with a depth that otherwise is impossible. Then once you've created something, you inevitably want to share it. In the sharing, you discover new things about it, and now you're changing your belief.

This excerpt underscores the twofold value of creative assignments in ministry training settings. The speaker discusses elsewhere that students need media creation skills in order to 'give people access to a [religious] tradition' in the midst of their work as religious educators. Yet here the emphasis is on the value of media-making in terms of self-discovery and the clarification of the creator's own ideas. In short, assigning media creation work in seminary classrooms allows instructors to model a valuable pedagogical approach that ministers can use in their own future ministry contexts.

We for years had three film festivals ... After we discontinued [them], I used to go down the village ... and people would stop me and say, 'Why aren't you running films anymore?' I said, 'Well, of course, you're all watching it on television now. They said, 'This festival had an important role in our lives. You were curating for us. [We] go into a video store, and there are 5,00o videos there. [We] can't see them all. [We] knew if [you] selected something and put it there, that it had been selected because it might be of interest to us.' I think that's a function that communities like ours have to think about, not simply to turn this over to the mass media.

This excerpt reminds us that faith leaders played the role of curator long before the emergence of new media. However, the preponderance of religious media in the years since the emergence of the Internet has made this task even more important.

Relevant ministry tasks:

- determine when to create new resources and when to share existing resources

- use media creation tools to create resources relevant to the context and people one serves

- choose the appropriate medium for sharing a particular message

- evaluate the theological appropriateness of faith resources found online

- collect and organize faith-related resources from a variety of sources 
Connecting media theory to theological reflection is a process of interdisciplinary connection and application that requires the ability to critically reflect on new media theory and practice from a theological point of view and on religious belief and practice from a media studies point of view.

They haven't had the opportunity, nor have they been pushed necessarily to think about some of the theology behind what they're doing ... there were lots of theological commitments and assumptions.

This interviewee was reflecting on a recent conversation with a religious app developer. The observation surfaces the way certain social, legal, and infrastructural logics are embedded when faith leaders participate in the new media ecology. It is by no means a given that these leaders are equipped to understand or even notice the theological, ethical, and ecclesial implications of these logics. ${ }^{40}$

I go through the media studies with them and say, 'Now if you have just taken their primary communication tool away from them [young people], even if that's the right thing to do, what is happening here?' ... I think for me I want to get students into the complexity of these issues both from the lived experience of the people showing up in their ministries as well as them as leaders making choices about how they will engage them.

If the first excerpt shows the temptation to overlook theological concerns, the second evidences insufficient engagement with the pragmatic realities of everyday new media communication. It reminds us of the importance of meeting the people we serve 'where they are' - and of not being too quick to dismiss new or unfamiliar practices as prima facie problematic.

Relevant ministry tasks:

- understand how new media ecologies work and how churches and faith leaders can participate in them intentionally and ethically

- apply theological themes, categories, and stories to understand digital media in new ways

- participate non-defensively in online theological discussions

- identify themes found in both theology and media theory (e.g., mediation, communication, presence, etc.)

40 In our reading, the need for this kind of noticing and questioning is precisely why a theological ethicist like Kate Ott commends increasing our participatory capacities for digital literacy as an appropriate Christian response to the various quandaries of inequity that new media so often raise. K. Ott, Christian ethics for a digital society, (Lanham, MD: Rowman \& Littlefield), 2019. 
- recognize the movement of the Holy Spirit in digital spaces, communities, and relationships

\subsection{Embodied Literacy}

Finally, we present a literacy to which each of the others contributes. We believe the ultimate purpose of all these literacies is to help ministry leaderslay and ordained - embody the values of their faith traditions and communities with integrity, grace, and an orientation toward serving others in healthy and responsive ways.

Presenting authentically and pastorally online is the ability to explore, claim, and 'inhabit' online spaces as a religious leader and pay particular attention to continuities and discontinuities with one's in-person identities. This literacy involves questions of authenticity, authority, vulnerability, professional boundaries, and intentional ethical conduct.

They may already be on social media for their own selves. They have to think about it differently when it's their church or their pastoral presence. Sometimes they do, and sometimes they don't.

This excerpt harkens back to the earlier point that it is by no means a 'given' (nor should we expect it to be) that personal experience with new media participation and creation should transfer seamlessly to the task of conducting oneself appropriately and effectively online as a religious leader. A goal of intentionally developing these literacies during seminary should be to close the gap between 'sometimes they do' and 'sometimes they don't.'

[We should be] empowering students to have some agency in how they use technology to get across their values, and their culture, and their message rather than imitating somebody else.

This excerpt reminds us that patterns of influence and leadership emerging in other online cultures and communities may not be appropriate for the values of religious communities. An especially subtle task in the enterprise of faithbased digital innovation is deciding what lessons to learn from prominent examples in other fields and what lessons to avoid or unlearn.

Relevant ministry tasks:

- align one's online communication with one's values

- conduct pastoral care via online communication tools - as necessary and appropriate 
- self-monitor and self-regulate tone and content of online posting in ways that align with one's leadership role

- present a non-idealized online persona consistent with one's offline presence

- identify and address potential online challenges to healthy interpersonal boundaries in ministry settings

\section{5} Implications \& Ongoing Work

The purpose of this paper has been to briefly survey prior work in theological education on the concept of and need for an approach to Christian leadership formation that considers digital literacy as an important outcome, and then to describe our qualitative analysis of interview data from a large sample of seminary and theological school instructors presently bringing such an approach to their work with their students. We believe the empirical identification of these seven digital literacies represents a potential shared foundation from which these and other educators may approach the tasks of classroom instruction, assignment development, curriculum and program analysis, etc. We make no claims that this is the "correct" or definitive list of literacies, ${ }^{41}$ only that it emerged from our analysis of the contributions of identified experts describing their practice and priorities, and then (in some cases) subsequently engaging in further conversation with us and each other about how to name and group them. We have found them robust and useful in our own subsequent seminary teaching and consulting, and these good responses have led us to begin a strategic program of resource development and follow-up research. These 'Phase Two' projects will examine these literacies "in action," including their impact as pedagogical foci within courses taught by theological educators. We also plan to make a formal argument for their coherence as a framework

41 Although we hasten to add that that it shares breadth and similar coverage with frameworks like Jenkins' and colleagues' new media literacies, and Niesyto's “central fields of competence" (p. 184) from the German schools context. Regarding the latter there is, for example, obvious consonance between our "navigating ..." plus "convening hybrid and digital community" and Niesyto's "[c]ommunication and cooperation with media" (p. 184). Jenkins, Purushotma, Weigel, and Clinton, Confronting the challenges of participatory culture; $\mathrm{H}$. Niesyto, 'Topics and key areas in current media pedagogical discussions,' in Religious education in a mediatized world, edited by I. Nord, and H. Zipernovszky, (Stuttgart, Germany: W. Kohlhammer), 2017, pp. 171-188. 
and to compare them with other overarching framework proposals from different fields and contexts.

In support of other educators who wish to use the digital literacies for ministry as outcomes in their own faith leadership preparatory courses, we have created a publicly available resource called the Digital Literacy Toolkit. ${ }^{42}$ This website describes the seven digital literacies identified and discussed in this paper and offers teaching practices, model assignments, and student support documents contributed by study participants and others. Some of the model assignments are discussed in more detail in a pedagogically oriented article that focuses on helping students develop the communal literacies. ${ }^{43}$ We are currently engaged in an ongoing multiple case study research project on professors' use of the literacies themselves, the toolkit resources, and the availability of digital literacy coaches to support faculty and students in the midst of this new learning.

The broad scope of ministry tasks, roles, and skills identified by our participants has convinced us that digital literacy has significant implications for anyone training for ecclesial leadership in today's church and media climate. Thus, a second focus of our continuing work lies in gathering feedback from leaders and trainees about how the concepts we identified in this work resonate with their experience. We have developed a validation survey that uses the ministry tasks listed with each literacy above as a way to determine practitioner perspectives on the literacies' definitions and relevance.

Moving forward, we hope other researchers, instructors, and practitioners will take up the digital literacies for ministry framework that emerged and was refined in the midst of this research, and join the conversation about an important but under-studied aspect of twenty-first century ministry.

\section{Acknowledgements}

We would like to thank the Arthur Vining Davis Foundation, the Episcopal Evangelism Society, and the Association of Theological Schools for their financial support of this ongoing research initiative. Thanks as well to Marjorie Baker and Sarah Stonesifer for their thoughtful feedback on this article.

42 K. M. Oliver, S. Williams-Duncan, and S. Stonesifer (eds), Digital literacy toolkit for theological educators, (2017). http://digitalliteracytoolkit.org/. 


\section{Biography}

Kyle Oliver is a doctoral candidate in Communication, Media, and Learning Technologies Design at Teachers College, Columbia University and works as a teacher, producer, and coach specializing in faith and media.

Stacy Williams-Duncan is a doctoral candidate in Curriculum and Instruction at the University of Virginia's Curry School of Education and serves as Interim Director of Digital Learning and Trotter Visiting Professor at Virginia Theological Seminary.

Lisa Kimball is the Associate Dean of Lifelong Learning and Professor of Christian Formation and Congregational Leadership at Virginia Theological Seminary and Director of the Lilly Endowment-funded Baptized for Life discipleship initiative. 